\title{
Judging a book by its cover: The unconscious influence of pupil size on consumer choice
}

\author{
Richard Wiseman \\ Psychology Department, University of Hertfordshire, College Lane, Hatfield, Hertfordshire AL10 9AB, UK; \\ e-mail: r.wiseman@herts.ac.uk
}

\section{Caroline Watt}

Psychology Department, University of Edinburgh, 7 George Square, Edinburgh EH8 9JZ, Scotland, UK Received 22 September 2010, in revised form 30 September 2010

\begin{abstract}
Past research suggests that men perceive women with large pupils as especially attractive. We employed an innovative methodology to examine whether this effect influences consumer decision-making. A popular psychology book was published with two slightly different front covers. Both covers contained the same photograph of a woman; however, the woman's pupils on one cover were digitally enlarged. Readers indicated whether they were male or female, and whether they possessed the cover with small or large pupils. A significantly greater percentage of men than women had chosen the cover with the large pupils. None of the participants who attempted to guess the nature of the experiment was correct, suggesting that the influence exerted by pupil size was unconscious. These findings provide further support for the notion that people's judgments are unconsciously swayed by pupil size, and demonstrate that this effect operates in a real world setting.
\end{abstract}

Research has consistently shown that people are unconsciously influenced by the size of another person's pupils, with perhaps the most robust relationship involving men rating women with large pupils as significantly more attractive than others (see, eg, Hess 1965; Stass and Willis 1967; Bull and Shead 1979; Tombs and Silverman 2004). Several neuropsychological studies suggest that this effect is, in part, due to observers unconsciously mimicking the pupil size of the person they are looking at, and that such 'social mirroring' is mediated by activity in the brainstem (see, eg, Harrison et al 2006; Demos et al 2008). In the present experiment we extend this laboratorybased work, examining whether subtle differences in pupil size can also unconsciously influence consumer decision-making in a real-world setting.

The first author wrote a popular psychology text (Wiseman 2007), and asked his publisher to design and produce two slightly different front covers for the book. Both covers contained the same two photographs of a smiling woman (one the correct way up, the other inverted); however, the woman's pupils on one cover were digitally enlarged (pupil diameters: small, $1.5 \mathrm{~mm}$; large, $2.5 \mathrm{~mm}$; iris diameter, $4 \mathrm{~mm}$ ). The books containing the larger pupils had a small $(5 \mathrm{~mm} \times 45 \mathrm{~mm})$ black rectangle unobtrusively printed on the back cover, while those with the smaller pupils carried an identically sized yellow rectangle. The publisher produced more covers with the large than small pupils (approximately 60:40 ratio), but ensured that the boxes used to distribute the books to national high-street stores and online retailers contained a random mix of the two covers.

The final page of the book invited readers to visit a website and take part in an online study, but revealed no further details about the experiment. Once online, respondents were asked to indicate whether they were male or female, the colour of the box on the back of their book, and whether they had purchased their book in a high-street store or online. Finally, participants were informed that the experiment concerned the book cover, and were asked to guess the nature of the study. 
All participants who indicated their sex, where they had purchased their book, and whether they had a black or yellow box on the back of their cover, were included in the analyses $(N=2329$ : 1627 male, 702 female).

As predicted from past research, the data from high-street purchases revealed that a significantly greater percentage of men than women had chosen the cover with the large pupils $\left(\chi_{1}^{2}\right.$ [with continuity correction] $=6.02, p=0.01, \phi=0.07$; see table 1$)$. None of the 576 respondents who attempted to guess the nature of the experiment was correct, suggesting that the influence exerted by pupil size was unconscious.

Table 1. Percentage and number (in parentheses) of men and women who had purchased the book in a bookstore, and chosen the cover containing large or small pupils.

\begin{tabular}{lll}
\hline & Large pupils & Small pupils \\
\hline Male & $64.96 \%(456)$ & $57.42 \%(240)$ \\
Female & $35.04 \%(246)$ & $42.58 \%(178)$ \\
\hline
\end{tabular}

It could be argued that this effect was not due to pupil size unconsciously affecting participants' choice of cover, but rather their decision to take part in the experiment. The data from online purchases allowed this hypothesis to be evaluated. If pupil size influenced participants' choice of cover, then the effect should be absent in the data from online purchases, as online retailers randomly allocated the books to customers. In contrast, if pupil size affected the decision to participate in the experiment, the effect should be present in the online purchase data. The data from participants purchasing their book online showed a non-significant relationship between sex and pupil size $\left(\chi_{1}^{2}\right.$ [with continuity correction] $=1.52, p=0.2, \phi=0.03$ : see table 2$)$, and thus supported the former interpretation. Once again, none of the 531 respondents who attempted to guess the nature of the experiment was correct.

Table 2. Percentage and number (in parentheses) of men and women who had purchased the book online, and chosen the cover containing large or small pupils.

\begin{tabular}{lll}
\hline & Large pupils & Small pupils \\
\hline Male & $62.05 \%(574)$ & $57.75 \%(164)$ \\
Female & $37.95 \%(351)$ & $42.25 \%(120)$ \\
\hline
\end{tabular}

These results suggest that consumer's choice was unconsciously influenced by very subtle differences in the size of the pupils of the woman on the cover of a book, causing significantly more men than women to select the cover containing larger pupils. Although the effect was relatively small, it provides further theoretical support for the notion that people's judgments are unconsciously swayed by pupil size, and demonstrates that this effect operates in a real-world setting. The study also builds on the first author's previous work exploring unusual ways of conducting large-scale studies in more ecologically valid settings (see, eg, Wiseman 1995; Wiseman et al 2003), and illustrates the efficacy of an innovative method that could be used to examine a range of additional factors in the future. In addition, the research adds to the literature concerned with the way in which consumer behaviour can be unconsciously influenced by subtle environmental and social cues (eg Dijksterhuis et al 2005). Finally, it provides the first empirical evidence to suggest that people do indeed judge a book by its cover. 
Acknowledgment. The authors would like to thank Macmillan Publishing for their invaluable help in conducting this study.

\section{References}

Bull R, Shead G, 1979 "Pupil-dilation, sex of stimulus, and age and sex of observer" Perceptual and Motor Skills $4927-30$

Demos K E, Kelley W M, Ryan S L, Davis F C, Whalen P J, 2008 "Human amygdala sensitivity to the pupil size of others" Cerebral Cortex $182729-2734$

Dijksterhuis A, Smith P K, Baaren R B van, Wigboldus D H J, 2005 "The unconscious consumer: Effects of environment on consumer choice” Journal of Consumer Psychology 15 193-202

Harrison N A, Singer T, Rotshtein P, Dolan R J, Critchley H D, 2006 "Pupillary contagion: central mechanisms engaged in sadness processing" Social Cognitive and Affective Neuroscience 15 - 17

Hess E H, 1965 "Attitude and pupil size" Scientific American 212(4) 46-54

Stass J, Willis F, 1967 "Eye contact, pupil dilation, and personal preference" Psychonomic Science $7375-376$

Tombs S, Silverman I, 2004 "Pupillometry: A sexual selection approach" Evolution and Human Behavior $25211-228$

Wiseman R, 1995 "The MegaLab truth test" Nature 373391

Wiseman R, 2007 Quirkology: The Curious Science of Everyday Lives (London: Macmillan)

Wiseman R, Watt C, Stevens P, Greening E, O'Keeffe C, 2003 "An investigation into alleged 'hauntings'” British Journal of Psychology 94 195-211 


\section{PERTEPTION}

VOLUME 392010

www.perceptionweb.com

Conditions of use. This article may be downloaded from the Perception website for personal research by members of subscribing organisations. Authors are entitled to distribute their own article (in printed form or by e-mail) to up to 50 people. This PDF may not be placed on any website (or other online distribution system) without permission of the publisher. 